\title{
Analysis of Curriculum Development Approach of National Curriculum for Chemistry Grade IX- X in Pakistan
}

\author{
Dr. Saghir Ahmad Ch. \\ Department of Education, Virtual University of Pakistan \\ Dr. Ayesha Batool \\ Assistant Professor, Lahore College for Women University Lahore, Punjab Pakistan
}

\begin{abstract}
The term curriculum is often used to only describe the goals, objectives, or plans. Each of these components is essential for effective learning. Curriculum improvement goes before its planning. It includes all partners or stakeholders in the education of the students and considers everything that will make the educational plan beneficiaries useful individuals from their general public. There are various ways to deal with curriculum improvement and development, which are exhibited by ones spotlight on the components of educational plan advancement and the degree of activity of the curriculum. This study was designed to analysis of curriculum development approach of National Curriculum for Chemistry Grade IX- X in Pakistan. The study was related to theoretical and content analysis based. National Chemistry Curriculum for grade IX-X is majorly based on subjectcentered curriculum. But on other hand to meet the need of society it demands to cope up with demands of technology. To enhance the skills of students, activities and construction of knowledge by on their own is stressed in aims of curriculum. Curriculum of Chemistry emphasis on developing higher order thinking and skills in students.
\end{abstract}

Keywords: Curriculum, stakeholders, education, chemistry, and students.

DOI: $10.7176 / \mathrm{JEP} / 12-13-07$

Publication date:May $31^{\text {st }} 2021$

\section{Introduction}

These descriptions are reliant on their various originations of training and the elements of school and the sorts of items they anticipate from instructive organizations. The basis of the word curriculum was from the Latin word 'currus', which intends to run a race. This implies once a kid begins to learn, he/she starts to run the race. This race is exhaustive in nature on the grounds that, throughout the race, the student experiences a ton of encounters, which might be scholarly, social, good, profound, divine or physical. These experiences are given to produce the absolute man. The experiences might be formal and arranged or casual and inadvertent or spontaneous. Over the span of the race, the youngster may likewise experience a few hindrances which he/she should surmount either through his/her endeavors or by the help of another person to empower him/her to accomplish the desires for the general public. The student is the primary focal point of the educational program and curriculum (Talla, 2012).

The term curriculum is often used to only describe the goals, objectives, or plans. Each of these components is essential for effective learning. Curriculum design should consider each of them as a piece. Curriculum (or curricula) is defined broadly to include four basic components as goals, methods, materials and assessment.

1.1 Goals:

The benchmarks or expectations for teaching and learning often made explicit in the form of a scope and sequence of skills to be addressed;

1.2 Methods:

The specific instructional methods for the teacher, often described in a teacher's edition;

1.3 Materials:

The media and tools that are used for teaching and learning;

1.4 Assessment:

The reasons for and methods of measuring student progress.

\section{Curriculum Development}

It manages the course of action of educational program materials to encourage execution. Ivowi (1994) considers developing educational plan and curriculum as planning of both, when he recognizes the three edges of curriculum: planning or development, execution and educational curriculum plan assessment. Curriculum improvement goes before its planning. It includes all partners or stakeholders in the education of the students and considers everything that will make the educational plan beneficiaries useful individuals from their general public.

\section{Curriculum Development Approaches}

Educational plan approach is a method for managing a curriculum, a method for 
doing/making/structuring/contemplating a curriculum. There are various ways to deal with curriculum improvement and development, which are exhibited by ones spotlight on the components of educational plan advancement and the degree of activity of the curriculum. Regardless of the methodology or structure or model, they all cover the similar degree expected or scope to build up a utilitarian curriculum. To develop or design a curriculum, its components are organized in certain patterns. As these patterns derived from the grounded philosophy of the country or need of the society. Through these parameters certain approaches remained focused to develop or design a curriculum. Literature also provided some approaches for curriculum development as:

1. Teacher- Centered Approach

2. Subject- Centered Approach

3. Student- Centered Approach

4. Eclectic Approach

Talla (2012) discussed the interconnected relationship of philosophy with the components of curriculum development i.e., objectives, content, methods of organization and evaluation. This relation is presented in the figure 1 .

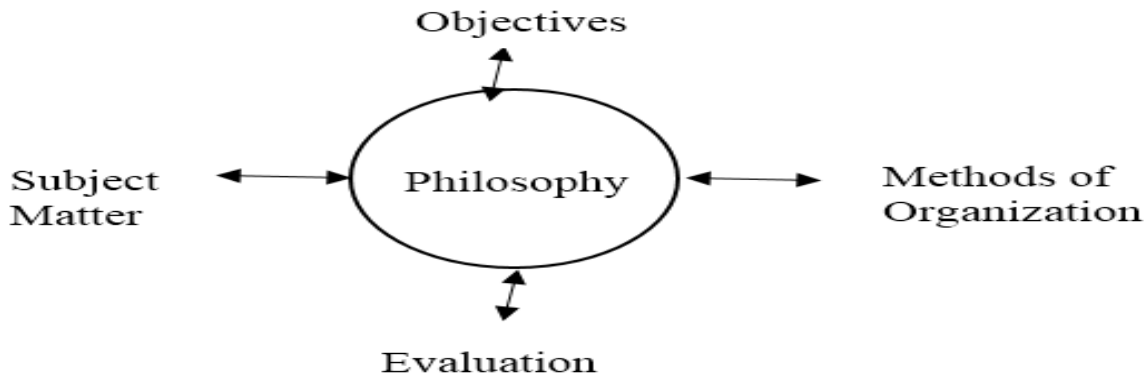

\subsection{Teacher-Centered Approach}

Figure 1: Relationship of philosophy with components of curriculum development

With the roots of idealistic philosophy and behaviorist school of thought, teacher- centered approach is focused to develop a curriculum. This is traditional way to develop or design a curriculum. As name reflects teacher occupies center position in this approach. Aims and objectives focused on developing students' behavior. One- way communication and passive learning occurred for transmission of knowledge.

\subsection{Subject- Centered Approach}

Basically, it focuses on nature of subject material. Natural sciences including chemistry, biology, physics, and mathematics are the subjects majorly demand to curriculum based on this approach. Teacher, here too, remained in central position, but flexible and active teaching take place. Students' demands to be curious and active learners to develop their higher order thinking capabilities.

\subsection{Student- Centered Approach}

Students remained in dominant position in this approach. Curriculum is developed to enhance students' skills and their potential by group works or individual projects. In literature this approach is further classified on two categories, i.e.,

Activity based/ Society based approach

Learner- centered approach/ Problem Solving approach

In both approaches student remains in dominant position. But difference among both is that in activity or society based approach mostly group works according to the needs and demand of society activities held on. On the base of pragmatist school of thought society remains focused. Curriculum is developed by focusing on the need and demand of the society. Students do activities, and investigations to create by on their own.

While in problem solving or student centered approach, existentialist school of thought reflects. Students' inner potential is nurtured. Students' create things by on their own and curriculum is designed great focused on the needs and demand of students at their particular age group.

\subsection{Eclectic Approach}

Eclectic approach is actually a blend or merging of two or more approaches. This blend can be focusing on dominating as major or minor share of approaches or could be with equal share in blending of two or more approaches.

\section{National Chemistry Curriculum}

It centers on substance, process abilities, critical thinking, request, and basic and explanatory reasoning aptitudes. This subject curriculum for class IX to XII expands on the vertical movement of the K-VIII Science Syllabus. It currently offers a moderately top to bottom investigation of Chemistry as a noteworthy, autonomous science. This offers an extreme move from the customary educational plan and curriculum. It characterizes of both vertical and horizontal sequence in spiral curriculum form of curriculum. 


\section{Aims and Objectives of Chemistry Curriculum}

Goals are broad statements of intended learning outcomes. They are stated using broad terms that are not measurable until they are broken down into action verbs. Objectives are specific statements of intensions of what is expected of the learners at the end of teaching session. They are stated in action verbs, which are measurable. Once the problems are identified the needs of the targeted group analyzed, the broad goals are formulated and broken down to specific objectives. In selecting the objectives, the three behaviors: cognitive, affective and psychomotor are born in mind. This is to ensure that the curriculum is comprehensive. The objectives drive every other activity in curriculum development. This is why it is important to use specific and clear action verbs to avoid misunderstanding. Objectives and destinations are significant in light of the fact that they help direct the decision of curricular substance; propose what learning strategies will be best; empower assessment of students and the educational plan; recommend what assessment techniques are suitable; obviously convey to others what the educational program delivers and would like to accomplish (Offorma, 2002).

National Chemistry Curriculum for grade IX- X is majorly based on subject- centered curriculum. But on other hand to meet the need of society it demands to cope up with demands of technology. Therefore, STS as Science-Technology-Society is focused in great deal. To enhance the skills of students, activities and construction of knowledge by on their own is stressed in aims of curriculum. In short this part is dominated with subjectcentered approach in whole based on eclectic approach.

The aim of this curriculum is to produce students who will be capable of doing independent thinking, asking questions, and looking for answers on their own (to be) competent in a complex, scientific and technological world society. It should therefore be evident that schools have a gigantic duty to get ready logically educated personnel. The key is to get ready youngsters with long lasting learning abilities to enable them to get a decent handle of the new information that they should endure (National Curriculum).

\section{Standards and Benchmarks of Chemistry Curriculum}

Curriculum of Chemistry emphasis on developing higher order thinking and skills in students. It concentrates on the subject matter along with it touching activities and STS links which again mix of more than one approach. But predominantly base on subject centered approach. There are three standards as mentioned in curriculum, i.e.,

1. Use of scientific knowledge,

2. Constructing new scientific knowledge and

3. Reflecting on scientific knowledge.

These standards further set their benchmarks accordingly. All standards and benchmarks are aligned with their approach as eclectic approach of subject and student centered (activity- based) approach, instead of one standard and benchmark. As Standard 1.1 reflects the eclectic approach while its set 5 benchmarks based on only subject-based approach.

\section{Contents of Chemistry Curriculum}

In the contents for IX- X, curriculum describes 16 chapters. These include chapter numbers with their names and respective headings and sub-headings accordingly.

\section{Learning Outcomes of Chemistry Curriculum}

In the learning outcomes, list of specific objectives with respect to the chapter is presented. It reflects the pure subject centered approach leading with the central position of the teacher.

This section of the curriculum gives detail description i.e., chapter number, name, list of major and minor concepts of the chapter. Conceptual linkage is also clearly mentioned in this document which represents the horizontal linkage with previous and upcoming grades.

Next declaring segment is prominence with skills and STS (Society- Technology-Science). Both sections are activity oriented, which determines the student centeredness regarding the activities and societal requirements. Therefore, all chapters' approach is eclectic in nature with dominating the subject centeredness.

\section{List of Practical, Chemicals and Equipment in Chemistry Curriculum}

The document of Chemistry curriculum also provides the list of practical associated with the chapter. It also mentions the related equipment and chemicals used to perform the practical activity. This represents the student activity approach which is demanded by the subject of study that's Chemistry. As Chapter 1, 5, 6, 7, 8, 10, 11, 12, 13 and 15 linked with practical part.

Based on 20 students' quantity of chemicals and amount of equipment (apparatus) is given. As Chemistry is the subject of science so it is connected with laboratory work. Therefore, activities in the form of practical are dominated with subject based. But because group work is performed during the activities and after performing them they would be enabled to construct their own thoughts as higher order thinking, therefore this also overlaps with student centered approach. In combine, mix of subject centered and little intersection of student centered, we 
got eclectic approach of content of Chemistry curriculum.

\section{Time Allocation in Chemistry Curriculum}

Chapter wise time allocation determines the number of teaching periods, assessments periods for evaluation and weightage percentage of each chapter. This shows the importance and the placement of each chapter in the book. High teaching periods number echoing the teacher centeredness but because this teaching is flexible in two-way communication therefore that is subject centered approach.

Assessment is again representing as traditional way, so here leading approach is teacher centered mix with subject centeredness.

\section{Teaching of Chemistry in Curriculum}

Educational strategies are the detailed means of facilitating learning. It involves the manipulations of the learning environment to motivate learners to learn. Implementation is putting into action, the planned curriculum. It calls for teacher-learner, learner-learner and learner-classroom environment interactions (Wheeler, 1978). In teaching the subject of chemistry, high role of teacher dominance in instructing the classroom and major focus is on teacher centered approach. But as it discusses to the chemistry content, talk about dialogue with student, give chance to develop high order thinking and scientific attitude represents the subject centeredness leads to student centered approach in point no.8.

In teaching- learning program curriculum address multiple approaches but greatly stressed on student centered approach. It represents that chemistry teaching learning calls for student centeredness but content must be concentrated. So students cannot get out from the boundary of subject centeredness. While rewarding opportunity in point no. 6 represents the behaviorist school of thought. Curriculum also discourses and offers some recommendations for teachers' training and refresher courses.

\section{Assessment and Evaluation in Chemistry Curriculum}

Evaluation deals with determining the success of the curriculum. Through the attainments of the learners, the strengths and weaknesses of the curriculum are identified and the feedback is used to update the curriculum. Appropriate instruments are developed and used to evaluate the attained curriculum. The feedback is used to restructure, modify, review or the curriculum (Offorma, 2002).

Traditional mode of assessment and evaluation is existing in curriculum as summative assessment. Along with it drawback is given to fill up this trendy fashion with continuous formative assessment which is strength of curriculum document. This would lead to subject centered approach further modified towards student centered to enhance the responsibility among them. Curriculum document also shares the plan of formative assessment and weightage of evaluation strategy. This evaluation weightage illustrates chapter wise distribution. Higher traditional and lower practical skills assessment lead to teacher centered approach which is $60 \%$. Higher abilities only $40 \%$ assessed that based on subject-center approach.

\section{Research Objectives}

The study was conducted to achieve the following objectives to:

1. This study was designed to analysis of curriculum development approach of National Curriculum for Chemistry Grade IX- X in Pakistan. The study was related to theoretical and content analysis based.

\section{Conclusion and Recommendations}

National Curriculum for Chemistry grades IX- X, 2006 reflects the eclectic approach. It is dominant with subjectcentered while assessment is leading with traditional and on teacher- centered approach. On other hand from the beginning of the aims and objectives throughout curriculum emphasis on higher thinking abilities along with STS and student activities.

Table 1

Approach used in Developing and Designing Chemistry Curriculum

\begin{tabular}{|c|c|}
\hline $\begin{array}{l}\text { Component of } \\
\text { Curriculum }\end{array}$ & Approach \\
\hline Aims and Objectives & Subject Centered +Student Centered (Activity, STS, Skills and Constructive) Approach \\
\hline Content & Subject Centered (High Teacher role) + Student Centered (Activity, Skills, STS) \\
\hline $\begin{array}{l}\text { Teaching } \\
\text { Classroom }\end{array}$ & $\begin{array}{l}\text { Traditional Teacher Centered Approach }+ \text { Subject Centered. This blend of equal } \\
\text { concentration }\end{array}$ \\
\hline $\begin{array}{l}\text { Assessment and } \\
\text { Evaluation }\end{array}$ & $\begin{array}{l}\text { Traditional Teacher Centered Approach }+ \text { Subject Centered. This blend of dilute } \\
\text { subject and minute student centered approach. }\end{array}$ \\
\hline
\end{tabular}

Analysis of National Curriculum of Chemistry 2006 reveals that it has been developed by using eclectic approach. The advancement of operative curriculum plan guide is a multi-venture, on-going and recurrent or 
cyclical procedure. There are many approaches to curriculum development. No matter the choice of approach, the curriculum developer must be guided $t$ by the following principles. The educational plan and curriculum designer must build up a philosophy and reasonable way of thinking and set larger objectives that guide the whole educational plan and the choices that influence every part of the curriculum. He ought to set up arrangements both inside and among levels and guarantee an intelligible and verbalized movement starting with one level then onto the next. An essential and primary structure must be laid out for what to do, how to do it, when to do it and how to know whether it has been accomplished. The educational program and curriculum must advance interdisciplinary methodologies and the incorporation when require. Techniques for surveying the accomplishment of the curriculum objectives and goals must be proposed and methods for update and improvement ensure. The direction for obtainment of personnel, material and financial assets to actualize and implement the educational plan and curriculum ought to be provided. There is no perfect approach. However, to be effective, an approach must attract acceptance of the teachers and other stakeholders in the education of the learners.

\section{References}

Approach (n.d.). Retrieved Feb 21th, 2017, from http://www.merriam webster.com/dictionary/approach

Curriculum (n.d.). Retrieved Feb 22th, 2017, from https://udlguidelines.wordpress.com/introduction/what-ismeant-by-the-term curriculum/

Curriculum approach (n.d.). Retrieved Feb 28th, 2017, from http://slideplayer.com/slide/3313060/

Curriculum basic concepts (n.d.). Retrieved Feb 28th, 2017, fromhttp://www.slideshare.net/deepati1/curriculumbasic concept?from_action=save

$\begin{array}{lllllll}\text { Curriculum models } & \text { (n.d.). } & \text { Retrieved } & \text { Feb } & \text { 28th, } & \text { 2017, } & \text { from }\end{array}$ http://www.slideshare.net/MhaiPalo/clipboards/curriculum-model

Government of Pakistan. (2006). National curriculum for chemistry at IX- X grades. Islamabad: Ministry of Education.

Ivowi, U.M.O. (2009). Concept of curriculum implementation. In Offorma (ed), Curriculum implementation and instruction. Onitsha: Uni World Educational Publishers.

Offorma, G.C. (2002). Curriculum theory and planning. Enugu: Donze Press.

Talla, M. (2012). Curriculum development: Perspectives, principles and issues. Pearson Education India.

Wheeler, D.K. (1978). Curriculum process. London: Hodder \& Stoughton. 